\title{
Changes in mitochondrial cytochrome $c$ oxidase mRNA levels with cataract severity in lens epithelia of Japanese patients
}

\author{
NORIAKI NAGAI ${ }^{1}$, YU MANO $^{1}$, HIROKO OTAKE $^{1}$, TEPPEI SHIBATA $^{2}$, ERI KUBO $^{2}$ and HIROSHI SASAKI ${ }^{2}$ \\ ${ }^{1}$ Department of Pharmacy, Kindai University, Higashi-Osaka, Osaka 577-8502; \\ ${ }^{2}$ Department of Ophthalmology, Kanazawa Medical University, Kanazawa, Ishikawa 920-0293, Japan
}

Received December 23, 2018; Accepted April 26, 2019

DOI: $10.3892 / \mathrm{mmr} .2019 .10214$

\begin{abstract}
We previously reported that the collapse of ATP production via mitochondrial damage causes ATPase dysfunction, resulting in the onset or progression of lens opacification in cataracts in model rats. In the present study, it was investigated whether the mRNA expression levels of the three subtypes of mitochondrial cytochrome c oxidase (MTCO)1, 2 and 3 and ATP content change with the type and severity of cataracts in human lens. Samples of lens epithelium were collected from Japanese patients during cataract surgery, and the type and severity of the cataracts (grade) were determined according to the WHO classification [cortical (COR), nuclear (NUC), posterior subcapsular (PSC) opacification]. The MTCO1-3 mRNA expression levels in patients with grade-1 COR, NUC and PSC opacification were significantly enhanced compared with those of normal patients. The enhanced MTCO1-3 mRNA levels subsequently decreased in patients with COR, and the MTCO1-3 mRNA levels and ATP levels in patients with grade-3 COR were similar to those in normal patients. However, the mRNA expression levels of MTCO3 in patients with grade 3-NUC opacification and MTCO1-3 in patients with grade-3 PSC opacification, along with the ATP content, were significantly lower than in patients without cataracts. In conclusion, it was revealed that ATP production in lens epithelium is enhanced in early-stage cataracts (grade-1) in Japanese patients with COR, NUC and PSC opacification. In addition, in severe cataracts (grade-3), ATP production and
\end{abstract}

Correspondence to: Dr Noriaki Nagai, Department of Pharmacy, Kindai University, 3-4-1 Kowakae, Higashi-Osaka, Osaka 577-8502, Japan

E-mail: nagai_n@phar.kindai.ac.jp

Abbreviations: $\mathrm{Ca}^{2+}$, calcium ion; $\mathrm{CCO}$, cytochrome c oxidase; COR, cortical opacification; HLE, human lens epithelial; $\mathrm{K}^{+}$, potassium ion; $\mathrm{Na}^{+}$, sodium ion; MTCO, mitochondrial cytochrome $\mathrm{c}$ oxidase; NUC, nuclear opacification; PCR, polymerase chain reaction; PSC, posterior subcapsular opacification; ROS, reactive oxygen species; RT, reverse transcription

Key words: cataract, cytochrome $c$ oxidase, ATP, human lens epithelium, mitochondria content are strongly decreased in Japanese patients with PSC opacification. ATP depletion in human lens epithelium with PSC opacification may promote lens opacification by ATPase dysfunction.

\section{Introduction}

Cataracts are the leading cause of blindness among the elderly population, and are enormous social and economic burdens for many countries (1-3). Diet, smoking, heritability, and corticosteroids are known risk factors for age-related cataract formation (4-6). Since the very detailed studies of Duncan and Bushell in 1975, it has been well-accepted that nuclear (NUC) cataracts show normal levels of sodium, potassium, calcium, magnesium and chloride (7). Thus, NUC cataracts are not considered to be of the osmotic type. In contrast, cortical cataracts show grossly increased levels of sodium and calcium with very low potassium levels, and are thus considered to be osmotic cataracts (7).

The ion balance in cortical cataractous lenses is unregulated, and the increase in the level of sodium ion $\left(\mathrm{Na}^{+}\right)$that occurs in age-related cortical cataracts points to a relationship between the degree of $\mathrm{Na}^{+}$increase and the severity of cortical opacification (COR) (8). In human age-related cortical cataractous lenses, $\mathrm{Na}^{+}$levels are abnormally elevated, while potassium ion $\left(\mathrm{K}^{+}\right)$levels are reduced. It has been reported that transparent human lenses contain approximately $17 \mathrm{mM} \mathrm{Na}^{+}$and $130 \mathrm{mM} \mathrm{K}^{+}$(9), while the $\mathrm{Na}^{+}$level is greater than $100 \mathrm{mM}$, and the $\mathrm{K}^{+}$level is about $80 \mathrm{mM}$ in cortical cataractous lenses (data as $\mathrm{mmol} / \mathrm{kg}$ lens water) $(7,10)$. These changes cause an osmotic disturbance so that water accumulates in cortical lens cells, and this leads to cell lysis and the appearance of fluid droplets that scatter light and impair transparency. In addition, the calcium ion $\left(\mathrm{Ca}^{2+}\right)$ level is also enhanced as cataracts develop in human lenses (transparent lens, $1.93 \mathrm{mM}$; cataractous lens, $33.3 \mathrm{mM}$ ) (11), and excessive $\mathrm{Ca}^{2+}$ levels accompany a derangement in lens $\mathrm{Na}^{+}$and $\mathrm{K}^{+}$levels in age-related human cortical cataracts (7). The accumulation of intracellular $\mathrm{Ca}^{2+}$ also induces the activation of apoptosis, a loss of cellular integrity, and the stimulation of proteolytic enzymes, all of which lead to COR (12). As a cause for these disturbances in the cortical cataractous lens, it is known that dysfunctions in ATPases, such as $\mathrm{Na}^{+} / \mathrm{K}^{+}$-ATPase and $\mathrm{Ca}^{2+}$-ATPase, play a role. The 
levels of $\mathrm{Na}^{+} / \mathrm{K}^{+}$-ATPase activity in the lenses of normal and cortical cataract patients are $6.6 \mathrm{Pi} \mu \mathrm{mol} / \mathrm{hr} / \mathrm{g}$ protein and 1.9 $\mathrm{Pi} \mu \mathrm{mol} / \mathrm{hr} / \mathrm{g}$ protein, respectively (13). In addition, we have reported that the $\mathrm{Ca}^{2+}$-ATPase activity in lenses decreases with the onset of lens opacification in the hereditary cataract model ICR rats, where the levels of $\mathrm{Ca}^{2+}$-ATPase activity in the transparent and opaque lens were $3.1 \mathrm{Pi} \mathrm{mmol} / \mathrm{hr} / \mathrm{g}$ protein and $1.4 \mathrm{Pi} \mathrm{mmol} / \mathrm{hr} / \mathrm{g}$ protein, respectively (14). The inhibition of $\mathrm{Na}^{+} / \mathrm{K}^{+}$-ATPase results in high intracellular $\mathrm{Na}^{+}$levels, and subsequent increases in intracellular $\mathrm{Ca}^{2+}$ ion through the $\mathrm{Na}^{+} / \mathrm{Ca}^{2+}$ exchanger (15). The enhanced intracellular $\mathrm{Ca}^{2+}$ levels are regulated by $\mathrm{Ca}^{2+}$-ATPase. These previous reports show that the regulation of ion balance by ATPases is needed to maintain lens transparency in cortical cataracts. On the other hand, the cellular changes that lead to the formation of posterior subcapsular cataracts (PSC) have been the least studied of all types of cataracts. The major risk factors associated with PSC are severe myopia, diabetes, and exposure to therapeutic doses of steroids and ionizing radiation; however, to our knowledge, there are no sufficient reports of biochemical analyses of human PSC (16).

Many researchers have reported on the mechanisms of ATPase dysfunction. We have also reported our findings using the lenses of hereditary cataract rats as models for human senile cataracts (UPLR and ICR rats) and cultured human lens epithelial (HLE) cells (14,17-19), and found 2 pathways leading to the disintegration of ion balance. One pathway involves oxidative stress via reactive oxygen species (ROS) that results in enhanced lipid peroxidation, leading to the inhibition of ATPase, and an increase in membrane permeability to $\mathrm{Na}^{+}$and $\mathrm{Ca}^{2+}$ in ICR lenses (14). The second pathway is one in which ROS injure the mitochondria, resulting in the collapse of ATP production. The decrease in ATP content causes ATPase dysfunction, resulting in an elevation in $\mathrm{Na}^{+}$and $\mathrm{Ca}^{2+}$ in UPLR lenses $(18,20)$. The elevation in $\mathrm{Ca}^{2+}$ levels via the 2 pathways leads to lens opacification. Therefore, it is very important to elucidate the changes in ATP production and ATP content during cataract development.

It is known that cytochrome c oxidase ( $\mathrm{CCO})$, which reduces oxygen to water and pumps protons across the inner mitochondrial membrane, plays an important role in ATP production. The three subtypes of mitochondrial cytochrome c oxidase (MTCO)1, 2 and 3 are the largest of the CCO subunits (21). Therefore, we investigated changes in the gene expressions of MTCO1-3 and ATP contents according to the type and severity of cataracts using lens epithelium collected from patients with 3 different types of opacification (COR, NUC opacification and PSC.

\section{Materials and methods}

Reagents. The ATP Bioluminescent Assay kit was obtained from Sigma-Aldrich; Merck KGaA (Darmstadt, Germany). The RNase-Free DNase set, RNA later ${ }^{\circledR}$ Solution and RNeasy Min kit were provided by Qiagen (Tokyo, Japan). The RNA PCR kit was purchased from Takara Bio Inc. (Shiga, Japan), and LightCycler FastStart DNA Master SYBR-Green I was provided by Roche Diagnostics Applied Science (Mannheim, Germany). All other chemicals used were of the highest purity commercially available.
Table I. Number of patients in each cataract group.

\begin{tabular}{lrll}
\hline Type & $\mathrm{n}$ & Type (mixed-cataract) & $\mathrm{n}$ \\
\hline COR & 35 & COR+NUC & 7 \\
NUC & 22 & COR+PSC & 2 \\
PSC & 8 & COR+NUC+PSC & 3 \\
& & NUC+PSC & 8
\end{tabular}

Cataract types were determined according to the WHO classification (22). The ages of normal and cataract patients were $63.1 \pm 3.8 \mathrm{y}$ (male $n=9$, female $n=9$ ) and 69.2 \pm 1.7 y (male $n=46$, female $n=39$ ), respectively. COR, cortical opacification; NUC, nuclear opacification; PSC, posterior subcapsular opacification.

Human lens epithelium samples. The human lens epitheliums were provided from patients agreed to the use of their samples in scientific research, and their samples were collected during November 20,2014 from Jun 26, 2014. During surgery, the central part of the anterior lens capsule $(5 \mathrm{~mm}$ diameter) containing attached epithelial cells was isolated by the continuous curvilinear capsulorrhexis (CCC) method using forceps. Samples of nucleated lens epithelium were obtained from non-Alzheimer's and non-diabetes patients during cataract surgery at Kanazawa Medical University (Ishikawa, Japan). The type and severity of cataract (grade) were determined according to the WHO classification (22), and patients providing samples of enucleated lens epithelium with COR, NUC and/or PSC were screened for visual acuity in the clinic prior to surgery. Table I shows the number of cataract patients in each cataract type group. Lens epithelium from normal patients (transparent lens) was collected during cataract surgery combined with vitrectomy for macular holes or epiretinal membrane, and used as non cataractous controls (clear, normal lens, control). In this study, 18 samples were collected from patients with transparent lenses (age 63.1 \pm 3.8 years; male $\mathrm{n}=9$; female $\mathrm{n}=9$ ), and 85 samples from cataract patients (age $69.2 \pm 1.7$ years; male $n=46$; female $n=39$ ) were collected as cataractous lenses. The samples were divided in half at random, with one half used to measure mitochondrial gene expression (MTCO mRNA), and the other half to measure ATP content; Table II shows the donor (patient) characteristics of the two sample halves [measurement of MTCO mRNA; normal lenses 64.2 27.1 years (male $n=3$, female $n=3$ ), cataractous lenses 67.0 \pm 3.2 years (male $\mathrm{n}=17$, female $\mathrm{n}=19$ ); measurement of ATP: normal lenses $62.5 \pm 4.4$ $y($ male $n=6$, female $n=6$ ), cataractous lenses $70.8 \pm 1.7$ years (male $n=29$, female $n=20)$ ], and Fig. 1 shows an image of lens opacification monitored using an EAS and slit lamp microscope. MTCO mRNA levels and ATP contents were measured by the revers transcription-quantitative polymerase chain reaction (RT-qPCR) method and the luciferin-luciferase assay method, respectively. Samples for PCR were stored in RNA later ${ }^{\circledR}$ solution or liquid nitrogen, and samples for ATP measurement were placed in liquid nitrogen immediately after removal. All experiments were carried out in accordance with the ARVO guiding principles, and approved by the Kanazawa Medical University Research Ethics Committee (project identification code 96, 28 May 2014), and the Kindai University School of Pharmacy Committee for Research Ethics (project identification code 13-046, 7 September 2013). 
Table II. Characteristics of patients in this study.

\begin{tabular}{|c|c|c|c|c|c|c|}
\hline \multirow[b]{3}{*}{ Type } & \multicolumn{3}{|c|}{ Measurement of MTCO mRNA } & \multicolumn{3}{|c|}{ Measurement of ATP } \\
\hline & \multicolumn{3}{|c|}{$\mathrm{n}$} & \multicolumn{3}{|c|}{$\mathrm{n}$} \\
\hline & Grade-1 & Grade-2 & Grade-3 & Grade-1 & Grade-2 & Grade-3 \\
\hline COR & 5 & 6 & 6 & 11 & 10 & 9 \\
\hline NUC & 10 & 4 & 3 & 12 & 6 & 3 \\
\hline PSC & 3 & 4 & 7 & 3 & 3 & 4 \\
\hline
\end{tabular}

Cataract type and grade (grade 1-3) were determined according to the WHO classification (22). Measurement of MTCO mRNA: ages of normal and cataract patients were $64.2 \pm 7.1$ y (male $n=3$, female $n=3$ ) and 67.0 3.2 y (male $n=17$, female $n=19$ ), respectively; measurement of ATP: ages of normal and cataract patients were $62.5 \pm 4.4$ y (male $n=6$, female $n=6$ ) and 70.8 \pm 1.7 y (male $n=29$, female $n=20)$, respectively. MTCO, mitochondrial cytochrome c oxidase; COR, cortical opacification; NUC, nuclear opacification; PSC, posterior subcapsular opacification.
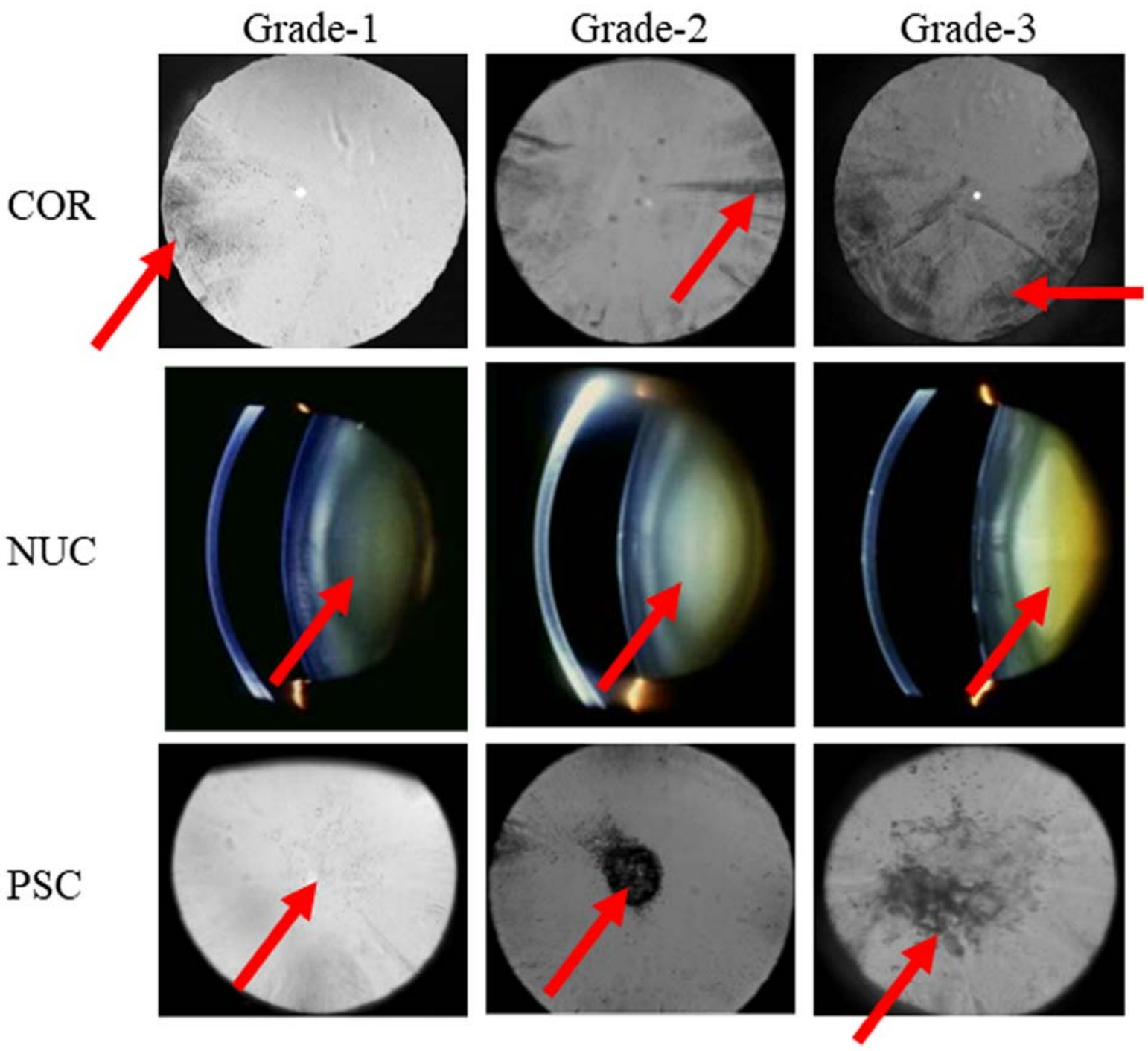

Figure 1. Representative images of lens opacification in patients. The images were monitored using the EAS and slit lamp microscope. Arrows indicated the defects observed in the patients. COR, cortical opacification; NUC, nuclear opacification; PSC, posterior subcapsular opacification.

$R T-q P C R$ method. Gene expression was measured using a LightCycler DX 400 according to the manufacturer's instructions and our previous report (23). Briefly, total RNA was extracted from the enucleated lens epithelium samples, and purified using an RNase-Free DNase Set and RNeasy Min Kit. Reverse transcription (RT) was carried out with an RNA PCR kit, and the PCR reaction was performed using LightCycler FastStart DNA Master SYBR-Green I. The RT reaction was 

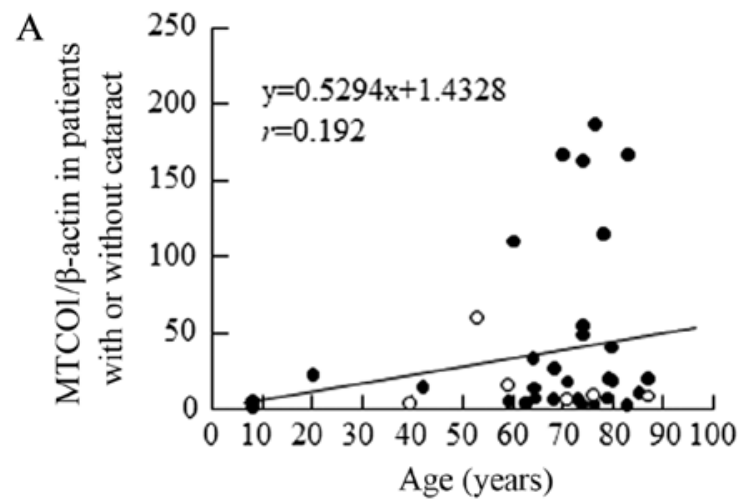

$\mathrm{C}$

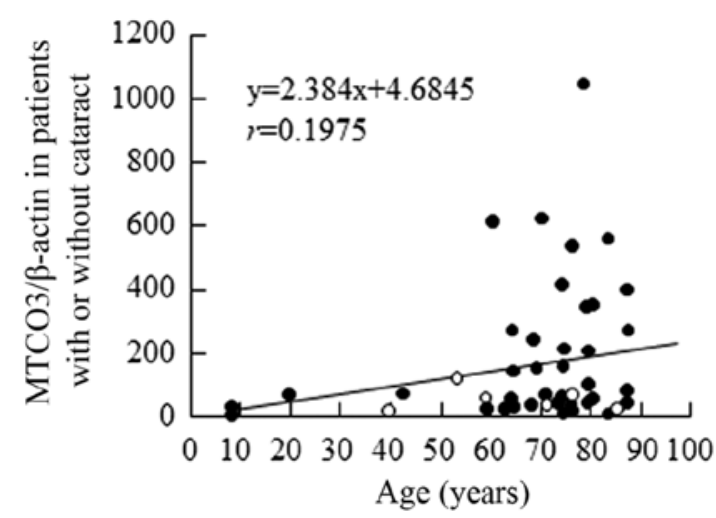

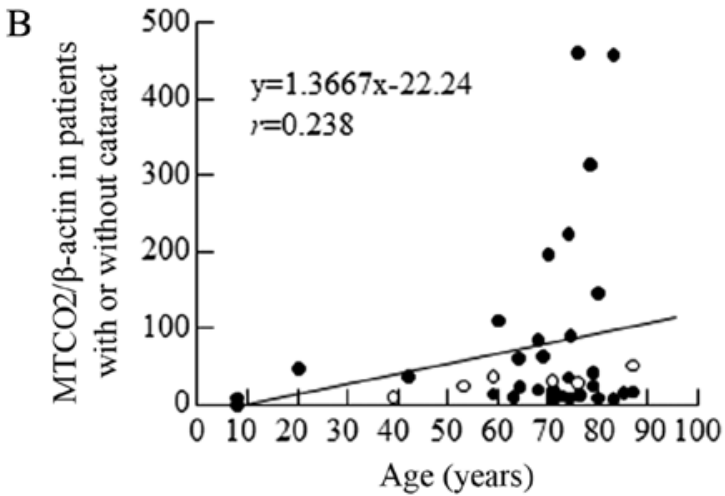

$\mathrm{D}$

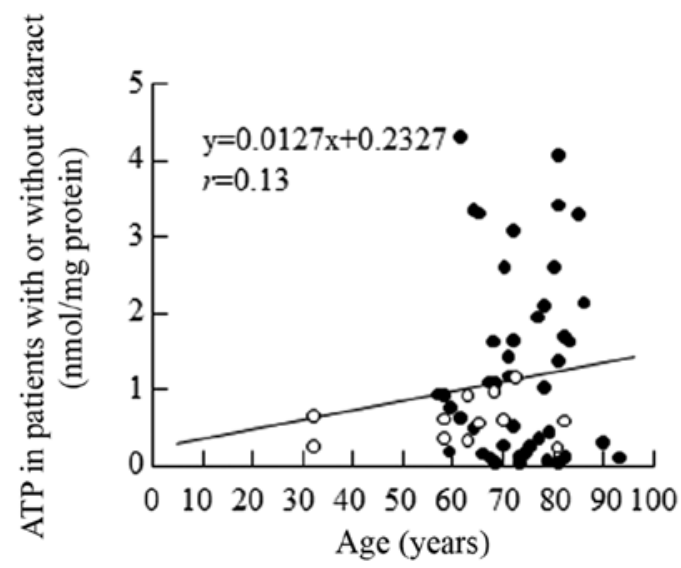

Figure 2. Association between age and MTCO (A) [MTCO1/ $\beta$-actin, (B) MTCO2/ $\beta$-actin and (C) MTCO3/ $\beta$-actin] mRNA expression levels and (D) ATP content in normal and opaque lens epithelium of Japanese patients. The patient characteristics are shown in Tables I and II (the data for Figs. 2A, B and C are all from the same lens epithelium samples, and include normal, COR, NUC, PSC, COR+NUC, COR+PSC, COR+NUC+PSC, and NUC+PSC. Open circles, transparent lens epithelium (clear, control); closed circles, opaque lens epithelium. MTCO, mitochondrial cytochrome c oxidase; COR, cortical opacification; NUC, nuclear opacification; PSC, posterior subcapsular opacification.

carried out at $42^{\circ} \mathrm{C}$ for $15 \mathrm{~min}$, followed by $5 \mathrm{~min}$ at $95^{\circ} \mathrm{C}$, and the conditions for PCR were as follows: $95^{\circ} \mathrm{C}$ for $10 \mathrm{~min}(\mathrm{Hot}$ start), 60 cycles of $95^{\circ} \mathrm{C}$ for $10 \mathrm{sec}$ (denaturing), $63^{\circ} \mathrm{C}$ for $10 \mathrm{sec}$ (annealing), and $72^{\circ} \mathrm{C}$ for $5 \mathrm{sec}$ (extension). In addition, the following specific primers (final concentration 10 pmol) were used: 5'-CCGTCCTAATCACAGCAGTCCTA-3' and 5'-TGA GGTTGCGGTCTGTTAGTAGT-3' for MTCO1; 5'-CCGCCA TCATCCTAGTCCTCAT-3' and 5'-GATCGTTGACCTCGT CTGTTATGT-3' for MTCO2; 5'-ACGGCATCTACGGCT CAACA-3'and 5'-TGGCGGATGAAGCAGATAGTGA-3' for MTCO3; 5'-GTGGCATCCACGAAACTACC-3' and 5'-CAG GGCAGTGATCTCCTTCT-3' for $\beta$-actin. The differences in the threshold cycles for target groups (MTCO1, 2 and 3) and $\beta$-actin were used to calculate the levels of mRNA expression in the human lens epithelium samples $(18,19,23)$. $\beta$-actin was detected in $24.6 \pm 0.5$ cycles, and the expression levels were similar among all normal and cataract patients with COR, NUC and PSC. On the other hand, the $\beta$-actin mRNA expression level was lower than that in widely used HLE cells $(12.3 \pm 0.8$ cycles, 23)

Measurement of ATP. ATP was measured by the luciferin-luciferase assay method $(18,19)$. Briefly, human lens epithelium samples were homogenized in $100 \mu$ l of saline, and centrifuged at $20,400 \mathrm{~g}$ for $15 \mathrm{~min}$. The resultant supernatant was assayed using an ATP Bioluminescent Assay Kit and a luminometer AB-2200 (Atto Corporation, Tokyo, Japan) according to the manufacturer's instructions. The protein levels were determined using a Bio-Rad Protein Assay Kit (Bio-Rad Laboratories, Hercules, CA, USA) with bovine serum albumin as the standard, and ATP levels are expressed as nmol/mg protein. The protein levels were $5.9 \pm 0.4 \mathrm{mg}$ with no significant differences among the normal and cataract patients with COR, NUC and PSC. There are previous reports that ATP levels in the total lens of humans is approximately $0.45 \mathrm{mmol} / \mathrm{g}$ lens (Iwata and Takehana, 1982), and the lens weight is approximately $200 \mathrm{mg}$. In this study, we used the central part of anterior capsule $(5 \mathrm{~mm}$ diameter) with lens epithelial cells (approximately $10 \mathrm{mg}$ ) for the measurement of ATP levels, and found total ATP levels of approximately $4.13 \mathrm{nmol} / \mathrm{sample}(82.6 \mathrm{nmol} / 200 \mathrm{mg}$, $0.41 \mathrm{mmol} / \mathrm{g}$ ) in agreement with the previous report.

Statistical analysis. All data are expressed as the mean \pm S.E.M, and unpaired Student's t-test, Aspin-Welch's t-test, or one-way ANOVA followed by Dunnett's multiple comparison were used for statistical comparisons. $\mathrm{P}<0.05$ was considered to indicate a statistically significant difference.

\section{Results}

Effect of age and gender on MTCO gene expression in lens epithelium of cataract patients. Before we investigated whether mitochondrial function changes in lenses according to the type and severity of cataract, we demonstrated the effects of age 

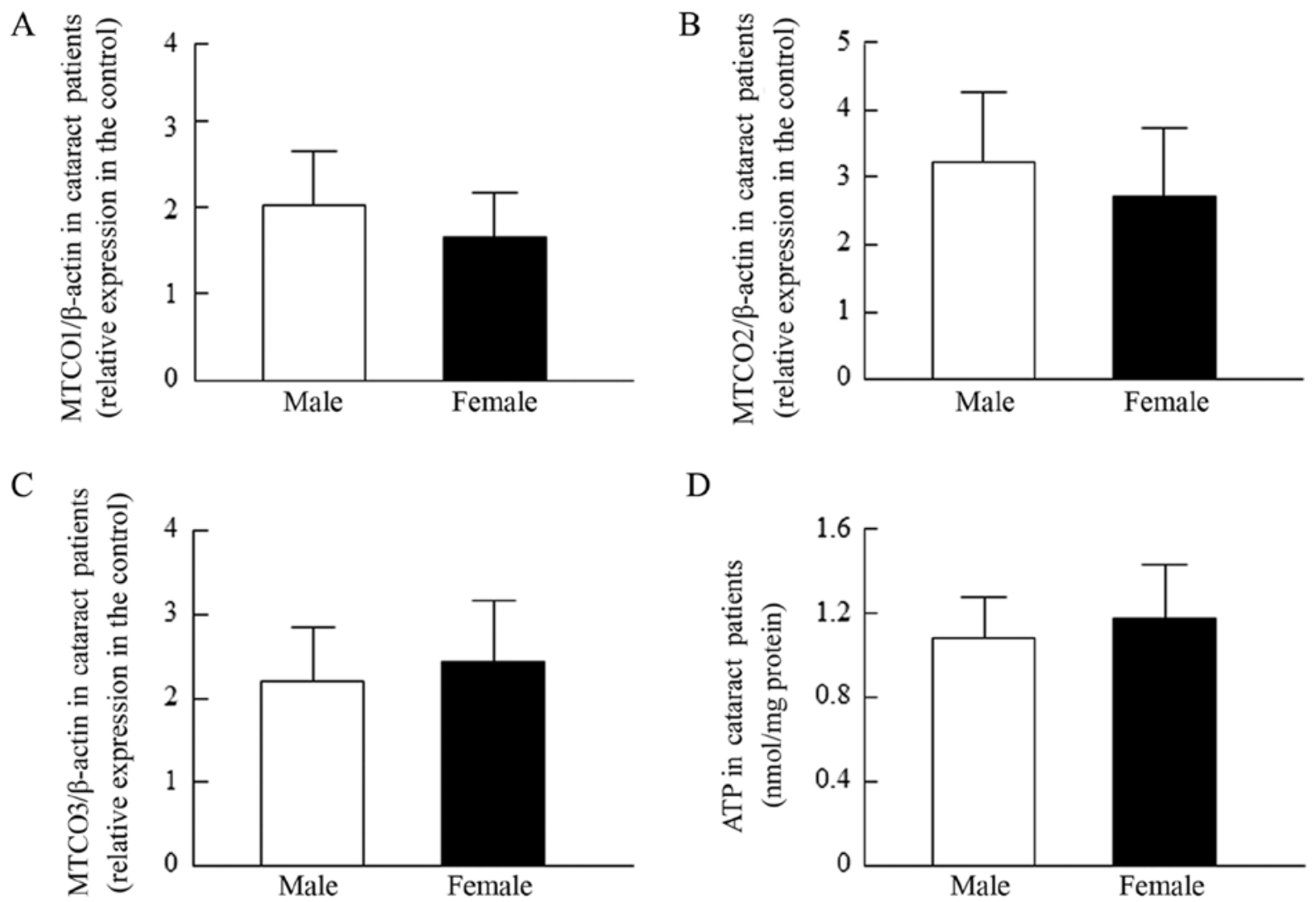

Figure 3. MTCO [(A) MTCO1/ $\beta$-actin, (B) MTCO2/ $\beta$-actin and (C) MTCO3/ $\beta$-actin] mRNA expression levels and (D) ATP content in the lens epithelium of male and female patients with cataracts. The patient characteristics are shown in Tables I and II (the data for Figs. 3A, B and C are all from the same lens epithelium samples, and include COR, NUC, PSC, COR+NUC, COR+PSC, COR+NUC+PSC, and NUC+PSC). The MTCO mRNAs were expressed as the relative expression in the control. The findings indicated that sex is unrelated to the MTCO mRNA levels or ATP content of lens epithelium. MTCO, mitochondrial cytochrome c oxidase; COR, cortical opacification; NUC, nuclear opacification; PSC, posterior subcapsular opacification.

and gender on the MTCO mRNA and ATP contents of lens epithelium from cataract patients. Fig. 2A-C shows the correlation between MTCO gene expression in lens epithelium and age, confirming that MTCO mRNA levels in cataractous lens epithelium do not change with age ( $r$ values for MTCO1, 2, 3 vs. age: $0.192,0.238$ and 0.1975 , respectively). In addition, age had no effect on the ATP content of cataractous lens epithelium (Fig. 2D, $r=0.13$ ). Fig. 3 shows no differences in the MTCO mRNA levels and ATP contents of lens epithelium between male and female cataract patients.

Changes in mitochondrial function in lens epithelium in relation to cataract severity in patients with COR, NUC and PSC. Figs. 4-6 show the MTCO1, MTCO2, and MTCO3 mRNA levels and ATP contents in relation to the grade of COR (Fig. 4), NUC (Fig. 5) and PSC (Fig. 6) in cataract patients. For patients with COR, the MTCO1-3 mRNA levels are significantly enhanced in grade- 1 cataracts, while the ATP content is increased in grades-1 and 2. At more advanced stages, the levels appear to normalize. Similar to the results for patients with COR, the MTCO1-3 mRNA levels in the lens epithelium of patients with NUC, were significantly higher in grade-1, and the ATP content tended to be enhanced in grades-1 and 2; however, the MTCO3 mRNA level was obviously decreased in grade-3 NUC, and the ATP content in grade-3 NUC was significantly lower than in normal lens. In the lens epithelium of patients with grade-1 PSC, both the MTCO1-3 mRNA levels and ATP content were significantly enhanced, but subsequently, the levels decreased. In grade-3 PSC, the MTCO1-3 mRNA levels and ATP content of the lens epithelium were significantly lower than in normal lens.

\section{Discussion}

The disintegration of ion balance in the lens causes opacification, resulting in blurred vision and blindness. We previously reported that decreases in ATPase activity and function leads to ion balance disintegration in the lens of models for human senile cataracts and in HLE cells, and that the decreases in ATPase activity and function are caused by lipid peroxidation and the collapse of ATP production via mitochondrial damage by the ROS stimulation, respectively $(14,17-19,23)$. However, there is no report on mitochondrial function in the lens as it relates to cataract severity. In the present study, we demonstrate the changes of MTCO mRNA levels and ATP content according to the type and severity of cataracts using lens epithelium from patients with 3 different types of opacification (COR, NUC and PSC). We have found that the MTCO and ATP contents (ATP production) in the lens epithelium is enhanced in early-stage cataracts (mild cataracts), while ATP production is decreased in severe cataracts. The decrease in ATP production may precede lens opacification.

ATP production takes place in the mitochondria, and $\mathrm{CCO}$, the terminal enzyme in the mitochondrial respiratory 
A

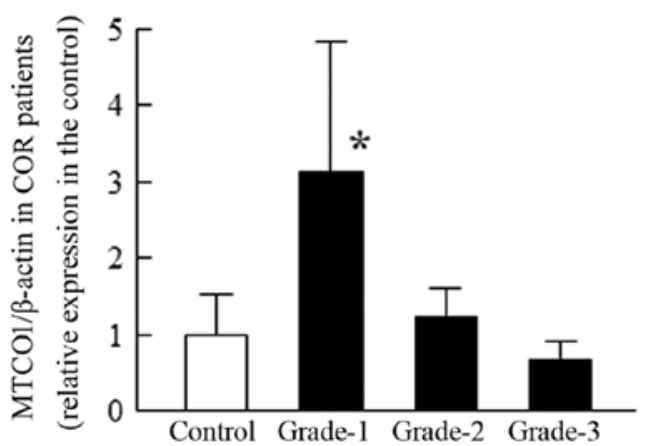

$\mathrm{C}$

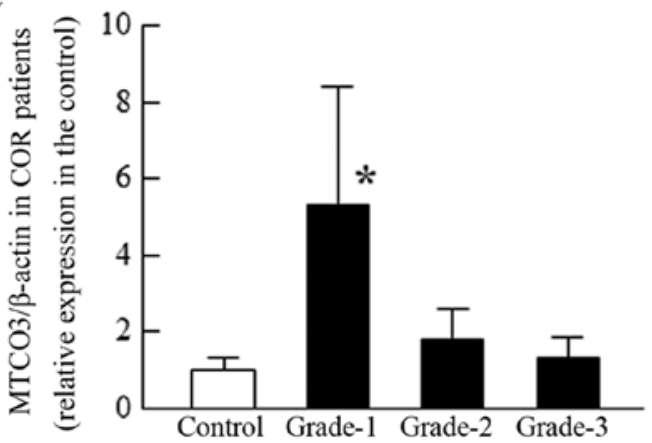

$\mathrm{B}$

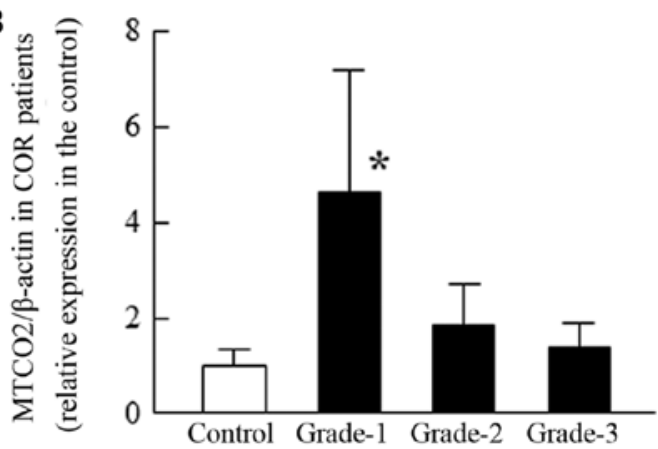

D

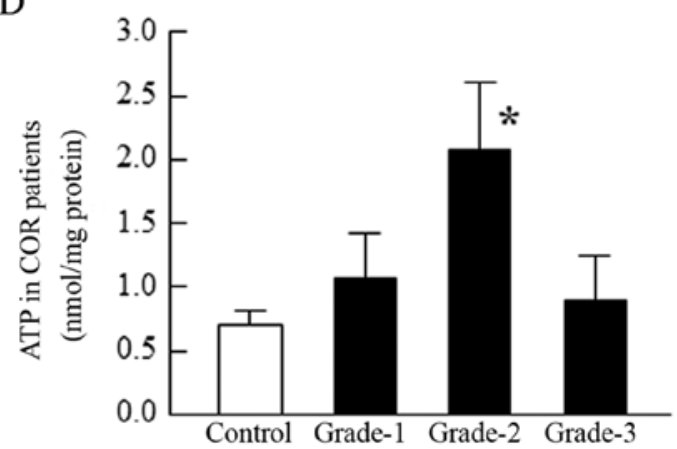

Figure 4. Changes in MTCO [(A) MTCO1/ $\beta$-actin, (B) MTCO2/ $\beta$-actin and (C) MTCO3/ $\beta$-actin] mRNA expression levels and (D) ATP content according to the opacity grade of patients with COR. MTCO and ATP levels were measured in the epithelium of COR patients. The patient characteristics (grade-1,2, and 3) are shown in Tables I and II, and the MTCO mRNAs were expressed as the relative expression in the control. Open columns, transparent lens epithelium (clear, control); closed columns, opaque (grade-1, 2, and 3) lens epithelium. $n=5-12 .{ }^{*} \mathrm{P}<0.05$, vs. control. The MTCO1-3 mRNA levels were significantly enhanced in grade-1 COR, and ATP content was significantly elevated in grade-2 COR; subsequently, the levels normalized. MTCO, mitochondrial cytochrome c oxidase; COR, cortical opacification; NUC, nuclear opacification; PSC, posterior subcapsular opacification.

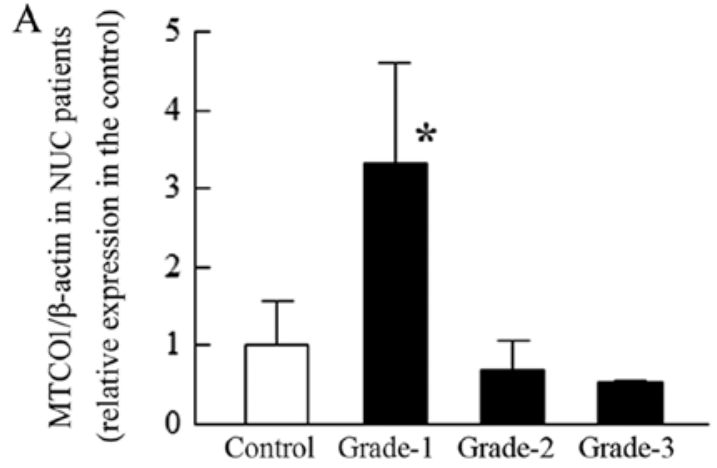

$\mathrm{C}$

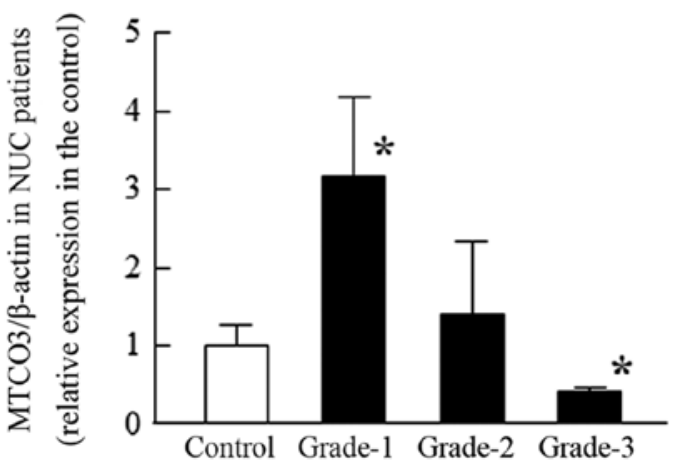

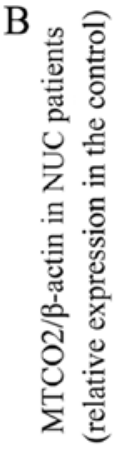

$\mathrm{D}$

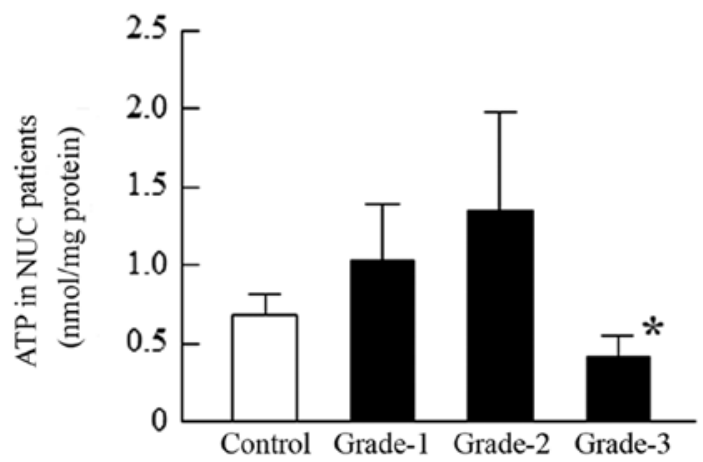

Figure 5. Changes in [(A) MTCO1/ $\beta$-actin, (B) MTCO2/ $\beta$-actin and (C) MTCO3/ $\beta$-actin] mRNA expression levels and (D) ATP content according to the opacity grade of patients with NUC. MTCO and ATP levels were measured in the epithelium of NUC patients. The patient characteristics (grade-1,2, and 3) are shown in Tables I and II, and the MTCO mRNAs were expressed as the relative expression in the control. Open columns, transparent lens epithelium (clear, control); closed columns (grade-1, 2, and 3), opaque lens epithelium. $n=3-12$. "P<0.05, vs. control. The MTCO1-3 mRNA levels in grade-1 NUC were significantly enhanced, and the ATP content also tended to be increased in grade-1 and grade-2 NUC. However, in grade-3 NUC, the MTCO3 mRNA levels and ATP content were significantly lower than in normal patients. MTCO, mitochondrial cytochrome c oxidase; NUC, nuclear opacification; PSC, posterior subcapsular opacification. 

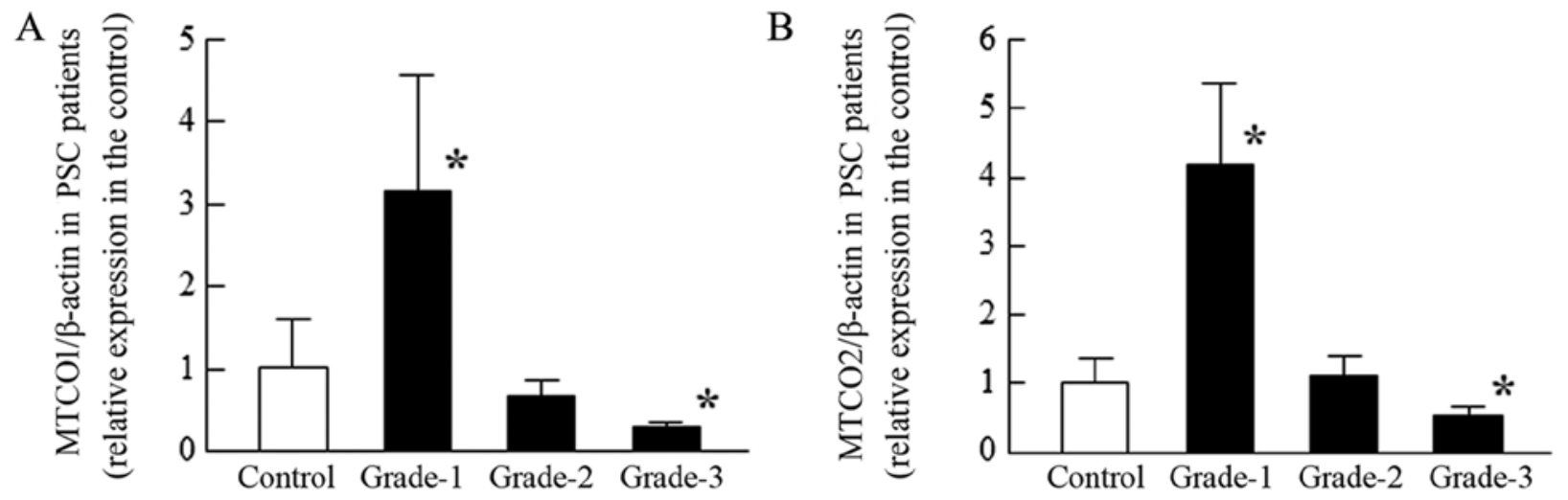

$\mathrm{C}$

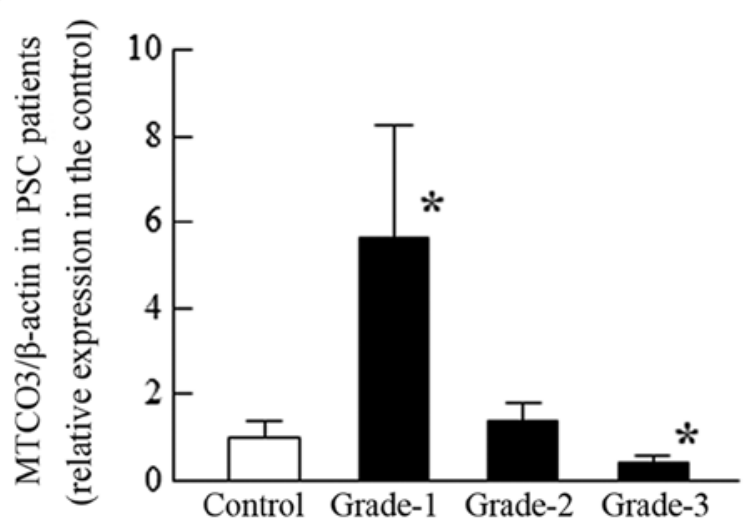

$\mathrm{D}$

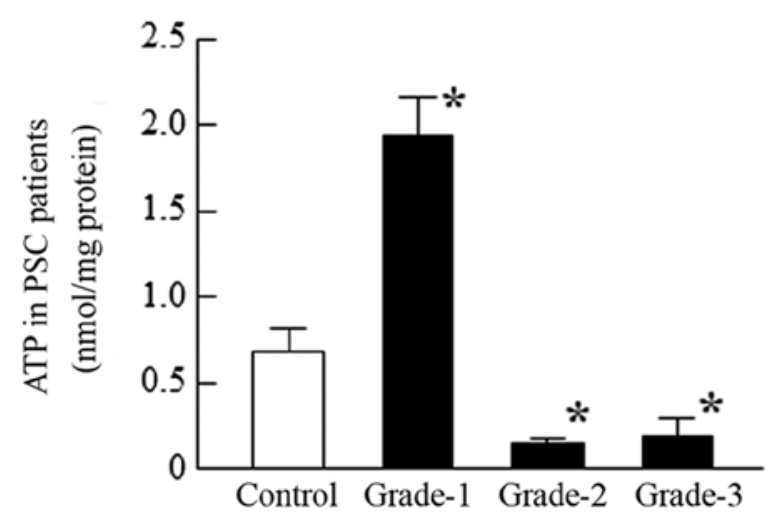

Figure 6. Changes in [(A) MTCO1/ $\beta$-actin, (B) MTCO2/ $\beta$-actin and (C) MTCO3/ $\beta$-actin] mRNA expression levels and (D) ATP content according to the opacity grade of patients with PSC. MTCO and ATP levels were measured in the epithelium of PSC patients. The patient characteristics (grade-1, 2, and 3) are shown in Tables I and II, and the MTCO mRNA were expressed as the relative expression in the control. Open columns, transparent lens epithelium (clear, control); closed columns (grade-1, 2, and 3), opaque lens epithelium. $\mathrm{n}=3-12$. ${ }^{*} \mathrm{P}<0.05$, vs. control. The MTCO1-3 mRNA expression levels and ATP content in grade-1 PSC were enhanced. On the other hand, in grade-3 PSC, the MTCO1-3 mRNA levels and ATP content were significantly lower than in normal patients. MTCO, mitochondrial cytochrome c oxidase; PSC, posterior subcapsular opacification.

chain, plays an important role in ATP production. $\mathrm{CCO}$ contains 13 subunits per monomer. Of these, CCO-4, 5a, $5 \mathrm{~b}, 6 \mathrm{a}, 6 \mathrm{~b}, 6 \mathrm{c}, 7 \mathrm{a}, 7 \mathrm{~b}, 7 \mathrm{c}$ and 8 (10 subunits) are synthesized on cytoplasmic ribosomes and imported into the mitochondria (24-27). These 10 subunits are encoded in the nuclear DNA. On the other hand, the remaining three subunits (mitochondrial subunits, MTCO) are encoded in the mitochondrial genome, and these catalytic subunits are the largest of the CCO subunits (mitochondrial CCO, MTCO). The three MTCO subunits (MTCO1, 2 and 3) are down-regulated earlier and more severely than the 10 subunits synthesized on cytoplasmic ribosomes (nuclear subunits) in response to functional inactivation (21). Based on these previous reports, we measured the gene expression of mitochondrial genome (MTCO1, 2 and 3) as an indicator of ATP production in this study. In addition, we determined the ATP contents in the lens epithelium of Japanese patients.

First, we investigated whether the ATP production and content in the central lens epithelium differs by age (Fig. 2) or gender (Fig. 3). There was no correlation between any of the three MTCO mRNA levels and age in lens epithelium of Japanese patients (MTCO1, $r=0.192$; MTCO2, $r=0.238$; MTCO3, $r=0.1975)$, and no differences were observed between males and females (Fig. 3). In addition, the $r$ value for the ATP content vs. age was 0.13 , and the ATP contents in lens epithelium of patients with cataracts was also similar between males and females. From these results, we could ignore the differences in age and gender among the samples, and use them for the following investigation.

Next, we investigated the changes in MTCO mRNA levels and ATP content in lens epithelium according to the type and severity of cataract. It is commonly assumed that there are three major types of cataracts: COR, NUC, and PSC (28). Therefore, we classified the opacification as one of these three types, and measured the MTCO mRNA levels and ATP contents according to the grade as shown in Tables I and II.

For all three types of cataracts examined (COR, NUC and PSC), the MTCO mRNA levels in the lens epithelium peaked in grade-1, and subsequently decreased with increasing opacity (Figs. 4-6). The MTCO mRNA levels in the lens epithelium of patients with grade-3 PSC were significantly lower than in normal lens. The MTCO3 mRNA levels in the grade-3 NUC samples were also decreased in comparison with normal lens, but the levels in the grade-3 COR lens epithelium were similar to those in normal lens (Figs. 4-6). Moreover, the same result was found for the ATP content (the behavior of the MTCO mRNA levels and ATP content were both similar). These results suggest that ATP production in the lens epithelium of Japanese patients is enhanced in early-stage cataracts (mild cataracts), and that ATP production is decreased in 
severe cataracts. The peak in the MTCO mRNA levels was apparent in grade- 1 cataracts, while the peak in ATP content was observed in grades-1,2 COR and grade-2 NUC. CCO is a product of mitochondrial genomes (MTCO1, 2 and 3) and nuclear genomes (CCO-4, 5a, 5b, 6a, 6b, 6c, 7a, 7b, 7c and 8) (24-27), and we measured only the mitochondrial genomes by RT-qPCR methods. Therefore, the expression of MTCO mRNAs for the nuclear genomes and CCO activity may be related to a time lag. On the other hand, the decreased ATP levels may be preceded by altered ATP hydrolysis. The contribution of MTCO to ATP production and ATP hydrolysis in the lenses of Japanese patients will be examined in a future study.

It is important to discuss the mechanism for the increase and subsequent decrease in MTCO mRNA levels. The epithelial mRNA values for stage 1 cortical and nuclear cataracts are all significantly higher than those for normal epithelium (Figs. 4 and 5), even though cortical cataracts are osmotic while nuclear cataracts are not. Multiple factors likely contribute to the development of age-related cataracts $(13,29-31)$, and many different factors could have led to the observed changes in MTCO mRNA expression and ATP content $(18,19,23,32)$. For example, it has been reported that ATP production in the lens of UPLR is enhanced by mild oxidative stress, such as by nitric oxide (protective mechanism), while excessive oxidative stress causes damage to the mitochondrial genome, resulting in a decrease in the ATP content of the lens $(20,32)$. Therefore, both changes (increase and decrease) in lens MTCO mRNA levels could be caused by ROS, and the differences in ROS levels in various parts of the lens may be related to the ATP contents as well as the cataract type and classification. In addition, it is necessary to discuss the relationship between mitochondrial dysfunction and the process of cataract development. Previous reports have shown that a decrease in ATP content via mitochondrial damage in the lens induces a decrease in $\mathrm{Na}^{+} / \mathrm{K}^{+}$-ATPase and $\mathrm{Ca}^{2+}$-ATPase function, with the resulting collapse in mineral balance enhancing the $\mathrm{Ca}^{2+}$ content of the lens. This enhanced $\mathrm{Ca}^{2+}$ level accelerates lens opacification $(11,13,18,19)$. In Japanese patients with COR, NUC and PSC, the MTCO mRNA levels are enhanced in early-stage cataracts, and then, in the case of NUC and PSC, decrease in severe cataracts (grade-3, Figs. 4-6). It has been reported that neither doubling the ATP concentration nor halving it has much impact on the $\mathrm{Na}^{+} / \mathrm{K}^{+}$-ATPase or $\mathrm{Ca}^{2+}$-ATPase activity of most cells (33-35). That the ATP level in grade-3 NUC is $60.7 \%$ that of normal patients support previous studies in which the development of NUC does not involve calcium alterations in the lens. Taking these findings together, we hypothesize that mitochondrial function is enhanced in early-stage cataracts by multiple factors, such as a protective mechanism against ROS. This enhanced mitochondrial function supports the regulation of ion balance in the mildly opaque lens. However, in severe PSC, the decrease in MTCO mRNA levels may promote the progression of lens opacification via a dysfunction in ATP production. Further studies are needed to confirm the mRNA and protein levels of other nuclear subunits of $\mathrm{CCO}$ (CCO-4, $5 \mathrm{a}, 5 \mathrm{~b}, 6 \mathrm{a}, 6 \mathrm{~b}, 6 \mathrm{c}, 7 \mathrm{a}, 7 \mathrm{~b}, 7 \mathrm{c}$ and 8 ), since the lack of the investigation of the protein expression of all the subunits of CCO as a limitation of the present study. In addition, it is important to elucidate the precise relationship between mitochondrial damage and cataract development. Therefore, we are now investigating the changes in ROS and CCO activity in the lens epithelium of Japanese patients, and will demonstrate the protein expression of $\mathrm{CCO}$ and localization of mitochondria in the opaque lens.

In conclusion, we measured the MTCO gene expression and ATP content in lens epithelium of Japanese patients with cataracts, and found that ATP production is enhanced in early-stage cataracts, and is then decreased in severe cataracts in comparison with transparent lens epithelium. ATP depletion in the case of grade-3 PSC may promote the development of lens opacification through a dysfunction in ATPase. However, these data all derive from Japanese patients; therefore, it is important to determine if these findings are applicable to other populations as well. These results provide significant information for the elucidation of the mechanisms of cataract development.

\section{Acknowledgements}

Not applicable.

\section{Funding}

The present study was supported by Daiwa Securities Health Foundation (Grant code 21).

\section{Availability of data and materials}

The datasets used and/or analyzed during the present study are available from the corresponding author upon reasonable request.

\section{Authors' contributions}

NN created the concept for the study, designed the protocol, and wrote the manuscript; YM and HO measured the ATP contents and mRNA levels; TS, EK and HS collected the enucleated lens epithelium (samples) during cataract surgery. All authors contributed to the conception and design of the study, and to the interpretation of the data.

\section{Ethics approval and consent to participate}

All experiments were carried out in accordance with the ARVO guiding principles, and approved by the Kanazawa Medical University Research Ethics Committee (project identification code 96, 28 May 2014) and the Kindai University School of Pharmacy Committee for Research Ethics (project identification code 13-046, 7 September 2013). Informed consent was obtained from patients

\section{Patient consent for publication}

Not applicable.

\section{Competing interests}

The authors declare that they have no competing interests. 


\section{References}

1. Angra SK, Murthy GV, Gupta SK and Angra V: Cataract related blindness in India \& its social implications. Indian J Med Res 106: 312-324, 1997.

2. Ezegwui IR, Aghaji AE, Uche NJ and Onwasigwe EN: Challenges in the management of paediatric cataract in a developing country. Int J Ophthalmol 4: 66-68, 2011.

3. Furtado JM, Lansingh VC, Carter MJ, Milanese MF, Peña BN, Ghersi HA, Bote PL, Nano ME and Silva JC: Causes of blindness and visual impairment in Latin America. Surv Ophthalmol 57: 149-177, 2012.

4. Leske MC, Chylack LT Jr and Wu SY: The lens opacities case-control study. Risk factors for cataract. Arch Ophthalmol 109: 244-251, 1991

5. Hammond CJ, Snieder H, Spector TD and Gilbert CE: Genetic and environmental factors in age-related nuclear cataracts in monozygotic and dizygotic twins. N Engl J Med 342: 1786-1790, 2000.

6. Iyengar SK, Klein BE, Klein R, Jun G, Schick JH, Millard C, Liptak R, Russo K, Lee KE and Elston RC: Identification of a major locus for age-related cortical cataract on chromosome 6p12-q12 in the beaver dam eye study. Proc Natl Acad Sci USA 101: 14485-14490, 2004.

7. Duncan G and Bushell AR: Ion analyses of human cataractous lenses. Exp Eye Res 20: 223-230, 1975.

8. Maraini G and Mangili R: Differences in protein and in the water balance of the lens in nuclear and cortical types of senile cataract. The Human Lens in Relation to Cataract. CIBA Foundation Symposium. Elliott K and Fitzsimons DW (eds) Elsevier, Amsterdam, Netherlands, pp79-95, 1973.

9. Patmore L and Duncan G: The physiology of lens membranes Mechanisms of Cataract Formation in the Human Lens. Duncan G (ed) Academic Press, London, England, pp193-217, 1981

10. Davies PD, Duncan G, Pynsent PB, Arber DL and Lucas VA: Aqueous humour glucose concentration in cataract patients and its effect on the lens. Exp Eye Res 39: 605-609, 1984.

11. Iwata $\mathrm{S}$ and Takehana N: Biochemical studies on human cataract lens. II. Opacity-related changes of cations, ATP and GSH in various types of human senile cataracts. Yakugaku Zasshi 102: 940-945, 1982 (In Japanese).

12. Gupta PD, Johar K and Vasavada A: Causative and preventive action of calcium in cataracto-genesis. Acta Pharmacol Sin 25: 1250-1256, 2004.

13. Iwata S: Crystalline Lens. Suishotai, in Japanease. Iwata S (ed) Medical-Aoi Publication Press, Tokyo, Japan, pp355-360, 1986.

14. Nagai N, Ito $\mathrm{Y}$ and Takeuchi N: Inhibitive effects of enhanced lipid peroxidation on $\mathrm{Ca}(2+)$-ATPase in lenses of hereditary cataract ICR/f rats. Toxicology 247: 139-144, 2008.

15. Blaustein MP: Endogenous ouabain: Role in the pathogenesis of hypertension. Kidney Int 49: 1748-1753, 1996.

16. Beebe DC, Holekamp NM and Shui YB: Oxidative damage and the prevention of age-related cataracts. Ophthalmic Res 44: $155-165,2010$

17. Nagai N, Ito Y, Takeuchi N Usui S and Hirano K: Comparison of the mechanisms of cataract development involving differences in $\mathrm{Ca}(2+)$ regulation in lenses among three hereditary cataract model rats. Biol Pharm Bull 31: 1990-1995, 2008.
18. Nagai $\mathrm{N}$ and Ito $\mathrm{Y}$ : Adverse effects of excessive nitric oxide on cytochrome c oxidase in lenses of hereditary cataract UPL rats. Toxicology 242: 7-15, 2007.

19. Nagai $\mathrm{N}$ and Ito $\mathrm{Y}$ : Dysfunction in cytochrome $\mathrm{c}$ oxidase caused by excessive nitric oxide in human lens epithelial cells stimulated with interferon- $\gamma$ and lipopolysaccharide. Curr Eye Res 37: 889-897, 2012.

20. Nabekura T, Tomohiro M, Ito Y and Kitagawa S: Changes in plasma membrane Ca2+-ATPase expression and ATP content in lenses of hereditary cataract UPL rats. Toxicology 197: 177-183, 2004.

21. Liang HL, Ongwijitwat S and Wong-Riley MT: Bigenomic functional regulation of all 13 cytochrome c oxidase subunit transcripts in rat neurons in vitro and in vivo. Neuroscience 140: 177-190, 2006.

22. Thylefors B, Chylack LT Jr, Konyama K, Sasaki K, Sperduto R, Taylor HR and West S; WHO Cataract Grading Group: A simplified cataract grading system. Ophthalmic Epidemiol 9: 83-95, 2002.

23. Nagai N, Ito $Y$, Shibata T, Kubo E and Sasaki H: A positive feedback loop between nitric oxide and amyloid $\beta$ (1-42) accelerates mitochondrial damage in human lens epithelial cells. Toxicology 381: 19-30, 2017.

24. Kadenbach B, Jarausch J, Hartmann R and Merle P: Separation of mammalian cytochrome c oxidase into 13 polypeptides by a sodium dodecyl sulfate-gel electrophoretic procedure. Anal Biochem 129: 517-521, 1983.

25. Kuhn-Nentwig L and Kadenbach B: Isolation and properties of cytochrome c oxidase from rat liver and quantification of immunological differences between isozymes from various rat tissues with subunit-specific antisera. Eur J Biochem 149: 147-158, 1985.

26. Taanman JW: Human cytochrome c oxidase: Structure, function, and deficiency. J Bioenerg Biomembr 29: 151-163, 1997.

27. Lenka N, Vijayasarathy C, Mullick J and Avadhani NG: Structural organization and transcription regulation of nuclear genes encoding the mammalian cytochrome c oxidase complex. Prog Nucleic Acid Res Mol Biol 61: 309-344, 1998.

28. Livingston PM, Carson CA and Taylor HR: The epidemiology of cataract: A review of the literature. Ophthalmic Epidemiol 2: 151-164, 1995.

29. Shearer TR, David LL, Anderson RS and Azuma M: Reviewof selenite cataract. Curr Eye Res 11: 357-369, 1992.

30. Dilsiz N, Olcucu A and Atas M: Determination of calcium, sodium, potassium and magnesium concentrations in human senile cataractous lenses. Cell Biochem Funct 18: 259-262, 2000.

31. Shun Shin GA, Bron AJ, Brown NP and Sparrow JM: The relationship between central nuclear scatter and perinuclear retrodots in the human crystalline lens. Eye (Lond) 6: 407-410, 1992.

32. Fariss MW, Chan CB, Patel M, Van Houten B and Orrenius S: Role of mitochondria in toxic oxidative stress. Mol Interv 5: 94-111, 2005.

33. Skou JC and Esmann M: Effects of ATP and protons on the $\mathrm{Na}$ : K selectivity of the $(\mathrm{Na}++\mathrm{K}+)$-ATPase studied by ligand effects on intrinsic and extrinsic fluorescence. Biochim Biophys Acta 601: 386-402, 1980.

34. Fu YF, Schuurmans Stekhoven FM, Swarts HG, de Pont JJ and Bonting SL: The locus of nucleotide specificity in the reaction mechanism of $(\mathrm{Na}++\mathrm{K}+)$-ATPase determined with ATP and GTP as substrates. Biochim Biophys Acta 817: 7-16, 1985.

35. Yang YC and Yingst DR: Effects of intracellular free $\mathrm{Ca}$ and rate of $\mathrm{Ca}$ influx on the Ca pump. Am J Physiol 256: C1138-C1144, 1989. 